\title{
Quality of life after hemicraniectomy for traumatic brain injury in adults
}

\author{
A review of the literature \\ Shabbar F. Danish, M.D., ${ }^{1}$ Dean Barone, P.a.-C., ${ }^{1}$ Bradley C. Lega, M.D., ${ }^{2}$ \\ and Sherman C. Stein, M.D. ${ }^{2}$ \\ ${ }^{1}$ Division of Neurosurgery University of Medicine and Dentistry of New Jersey-Robert Wood \\ Johnson Medical School, New Brunswick, New Jersey; and ${ }^{2}$ Department of Neurosurgery, \\ University of Pennsylvania Health System, Philadelphia, Pennsylvania
}

\begin{abstract}
Decompressive hemicraniectomy is well accepted for the surgical treatment of intractable intracranial hypertension in cases in which medical management fails. Although it is performed as a life-saving procedure when death is imminent from intracranial hypertension, little is known about the functional outcomes for these patients on long-term follow-up. In this study, the authors performed a systematic review of the literature to examine neurological outcome after hemicraniectomy. A literature search revealed 29 studies that reported outcomes using GOS scores. The GOS scores were transformed to utility values for quality of life using a conversion method based on decision analysis modeling. Based on the literature, 1422 cases were analyzed. The average 6-month-postoperative mortality rate was $28.2 \%$. The mean QOL value among survivors was 0.592 , which corresponds roughly to a GOS score of 4 . Although more studies are needed for validation of long-term neurological outcome after hemicraniectomy, the assumption that most patients remain in a vegetative state after this intervention is clearly incorrect. (DOI: 10.3171/2009.3.FOCUS945)
\end{abstract}

KEY WORDS • traumatic brain injury • hemicraniectomy • outcome

$\mathrm{H}$ EAD injury is a major cause of morbidity and mortality worldwide. Trauma itself is the leading cause of death in the first 4 decades of life, with traumatic brain injury being implicated in at least half the cases. ${ }^{13}$ One of the fundamental pathophysiological processes after traumatic brain injury is the development and propagation of an escalating cycle of brain swelling and an increase in ICP. The goals of the clinical management of severe head injury consist of interrupting this cycle by controlling ICP and maintaining cerebral perfusion pressure and cerebral blood flow to avoid brain ischemia. This management strategy has been developed as a result of reported strong correlations between uncontrollable high ICP and high rates of morbidity and mortality. The relationship between high ICP and poor outcome has been demonstrated consistently in both single-center and multicenter studies, and the ability to bring elevated ICP under control has long been considered a requirement for improving outcome of patients with severe head injuries. ${ }^{8,17,20,23}$ In an effort to reduce ICP, hemicraniectomy has evolved as a surgical option that has recently seen a "re-birth." Logically, it seems that opening a tight

Abbreviations used in this paper: GOS = Glasgow Outcome Scale; ICP = intracranial pressure; $\mathrm{QOL}=$ quality of life. skull would reduce ICP, improve blood flow, and reduce swelling, leading to reduced morbidity and mortality. This concept has yet to be proved, however, with respect to improvement in clinical outcome. ${ }^{30}$

Those who are skeptical of the procedure raise several questions. Does the craniectomy quantitatively control raised ICP? Does brain herniating through the defect escalate the problems? What prognostic information can we give the families of those for whom the procedure is being proposed? Do the results justify the treatment? The last question is the focus of this review. Because of the lack of prospective, randomized trials, debate exists over the clinical outcome expected for patients undergoing the procedure. Especially in centers where craniectomy has not gained acceptance, there is a notion that patients whose head injuries are severe enough to mandate hemicraniectomy persist with severe disability or in a vegetative state, rendering the procedure futile and wasteful. Furthermore, because most studies use GOS scores to report outcomes, results from different studies cannot be combined and simply averaged. Finally, we must ask if the growing experience with hemicraniectomy over the years has led to better outcomes.

The present work is a review of the literature with respect to outcomes following hemicraniectomy. By con- 
TABLE 1: Total number of patients in each GOS category 6 months postoperatively

\begin{tabular}{cc}
\hline GOS Score & No. of Patients \\
\hline 5 & 383 \\
4 & 283 \\
3 & 232 \\
2 & 110 \\
1 & 414 \\
\hline
\end{tabular}

verting GOS scores to utility values for QOL, we provide an average outcome for patients undergoing hemicraniectomy that is derived from the literature and is statistically sound.

\section{Methods}

A structured search of the English-language literature was performed to obtain the necessary data. A Medline search of all entries containing the subject heading "craniocerebral trauma" along with any combinations of the words "hemicraniectomy," decompression" (or "-ive"), or "craniectomy" was examined. The list was supplemented by reviewing the bibliographies of selected papers and using the "Related Articles" feature of PubMed. We decided to limit the analysis to series of at least 5 surgically treated cases, published between 1997 and December 2008 and containing GOS scores obtained at least 6 months after initial treatment. Series restricted to children $(<20$ years old) were not included; when identified separately, pediatric cases were removed from series containing both adults and children.

We converted GOS scores to measures of utility or QOL using the formula published by Aoki et al. ${ }^{3}$ The authors queried 135 healthcare professionals and elicited utilities for each of the GOS scores using a standard-gamble method. By convention, ${ }^{10}$ the utility of a normal state of health (equivalent to a GOS score of 5) is 1 , and that of death (GOS score, 1) is zero. The utilities or QOL values of intermediate GOS scores $0.63,0.26$, and 0.08 for GOS scores of 4,3 , and 2 , respectively. These numbers represent values of QOL proportional to the respective GOS scores. For each study, we calculated mean utility and variance from the distribution of GOS scores. We also calculated the mean year of patient accrual.

To calculate pooled means for patient survival and the QOL values of survivors, we used a random effects meta-analytical model applied to prevalence data. We used the "metan" function of Stata (StataCorp LP). We used the same techniques to calculate pooled mean percentage of favorable outcomes (GOS scores 4 or 5). To check for temporal trends, we regressed mean QOL values of each case series against the mean year of patient accrual, using the "metareg" function. We considered a probability value of $<0.05$ significant.

\section{Results}

Our Medline search yielded 269 English-language articles dealing either with hemicraniectomy or bifron- tal decompressive craniectomy for severe traumatic brain injury. Of these, the majority of reports dealt with laboratory research, aspects of the surgery rather than general results. Other publications were reviews, editorials, or duplicated previous reports.

We found 29 articles reporting 1422 cases involving adult patients in whom decompressions were performed. ${ }^{1,2,4-7,9,11,14-16,18,19,21,22,25,27-29,31-40}$ The mean years of patient accrual were between 1987 and 2005. Total numbers in each GOS category are shown in Table 1. Among survivors, the median GOS score was 4 . For the pooled data, the average 6-month postoperative mortality rate was $28.2 \%$ (range $23.5-33 \%$ ), and the mean QOL value among survivors was 0.592 (range $0.526-0.658$ ). This QOL value is quite close to that reported for a GOS score of moderate disability. ${ }^{3}$ The main outcomes are illustrated in Fig. 1. Overall, the pooled mean utility of decompressive craniectomy was 0.426 (95\% CI $0.362-0.490)$. This outcome value is the mean of values for surviving patients and those who died. Favorable outcomes (GOS scores of 4 or 5) were achieved by $63.3 \%$ of survivors (95\% CI 59.9-66.7\%). For the entire series, including nonsurvivors, $46 \%$ of outcomes were favorable $(95 \%$ CI $34.5-57.5 \%)$.

There did not appear to be any trend toward improvement of surgical outcomes between 1987 and 2005. Metaregression showed that there were no significant trends over time with respect to either mortality or QOL among survivors ( $p=0.429$ and 0.891 , respectively). This is also evident in Fig. 1, in which case series are presented from the above-described group of articles, in order of publication date.

\section{Discussion}

We reviewed more than 1400 reported cases of decompressive craniectomy performed in adults for the treatment of severe traumatic brain injury and uncontrollable intracranial hypertension. The pooled mean 6-monthpostoperative mortality rate for the series was approximately $28 \%$, and the pooled mean QOL value among the survivors was almost $60 \%$ of the value of a normal state of health. This score is very close to the QOL associated with moderate disability score (GOS score of 4). ${ }^{3}$ Favorable outcomes (GOS scores of 4 or 5 ) were reported for $46 \%$ of the series when all patients were considered, and $63 \%$ of survivors. Our data also indicate that neither mortality rate nor QOL have improved since the late 1980s, when the procedure regained popularity and saw renewed application to the treatment of ICP.

The findings from this study challenge the occasional charge that hemicraniectomy shifts the outcome from death to a persistent vegetative state and severe disability. Recent outcome studies of protocols including decompressive craniectomy have also not supported this concept. ${ }^{21,26}$ The mean QOL value of survivors after hemicraniectomy when all series were combined in our study places the average survivor in the moderate disability category. Based on our findings, it is reasonable to counsel families that many patients undergoing hemicraniectomy for uncontrollable ICP will be able to function independently. 


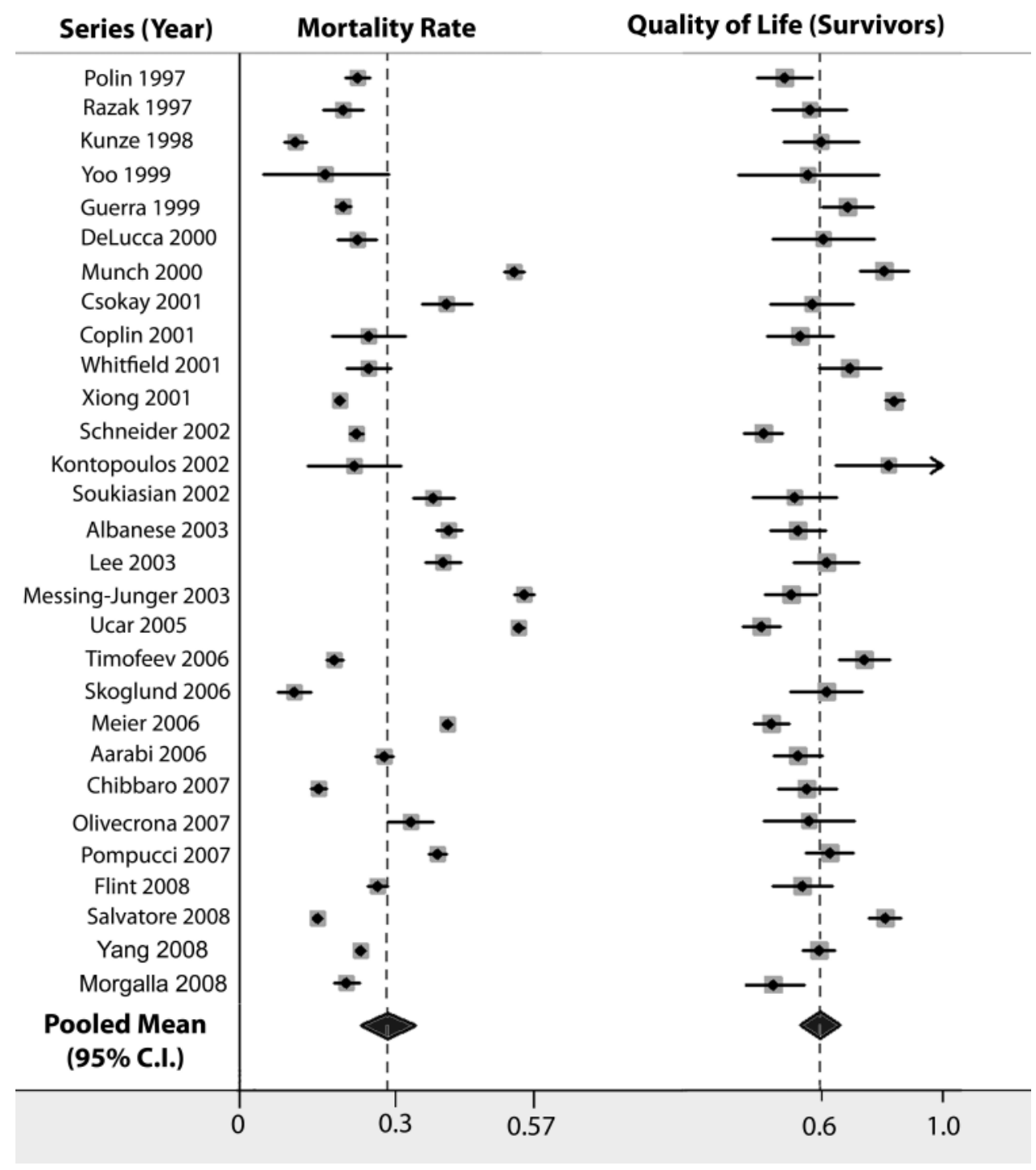

FIG. 1. Summary of mortality rates and QOL after hemicraniectomy. Twin Forest plots illustrating outcomes of decompressive craniectomy for severe traumatic brain injury in adults. Mortality rate is plotted on the left, QOL on the right. The first author and year of publication of each quoted report are listed to the far left. The center of each square represents the mean of that study, the horizontal bar its $95 \% \mathrm{Cl}$. The size of each box represents the weight of the study, and is inversely proportional to its variance. The pooled estimates are represented by the diamonds below. For each diamond, the center represents the pooled mean, the horizontal extent equals its $95 \% \mathrm{Cl}$.

There are a number of limitations in our study. The populations from which our data are drawn are heterogeneous in terms of patient characteristics, indications for surgery, and decompression techniques used. This heterogeneity limits the precision of our estimates. We cannot adjust for a number of clinical factors known to be associated with outcome, such as age, $1,11,15,21,27,28$ timing of surgery, ${ }^{15,24,27}$ admission GCS score, preoperative pupillary examination, and other features..$^{12,21}$ We chose QOL as an outcome measure over GOS scores because of its almost universal use in quantitative studies of medical outcomes ${ }^{10}$ and because of its conformance to mathematical calculations, such as determining mean values and confidence intervals. The GOS is an interval scale of neurological function; calculating mean GOS scores and other mathematical manipulations are meaningless. Converting a score to a parametric value of QOL has, at most, limited validity but at least allows valid mathematical and statistical calculations. Some might also question the conversion process used by Aoki and associates, ${ }^{3}$ in which preferences were those of health care professionals rather than the community. In addition the complication profile queried by Aoki et al. was drawn from aneurysm surgery rather than from hemicraniectomy. Some of the many complications of hemicraniectomy are transient and not reflected in the GOS scores at 6 months. ${ }^{39}$

Nevertheless, the data may prove useful in providing prognostic guidance when counseling family members about a decompression procedure. We cannot conclude that decompressive craniectomy is superior to medical 
care alone, because we did not compare outcomes. In addition, a recent Cochrane Review suggested that evidence is lacking. ${ }^{30}$ Any definitive conclusions about treatment comparisons must await the completion of the ongoing DECRAN and Rescue ICP trials. In the interim, the findings from this study should lend confidence to practitioners who use the procedure in the treatment of intractable ICP.

\section{Conclusions}

Decompressive hemicraniectomy is a well-known surgical option for uncontrollable intracranial hypertension. Although it lacks evidence from randomized trials, pooled outcomes from the current literature show that patients who undergo hemicraniectomy for severe traumatic brain injury can achieve a reasonably good QOL. In the future, the results of ongoing randomized trials should reveal the patient population in which this intervention can make the largest impact.

\section{Disclaimer}

The authors report no conflict of interest concerning the materials or methods used in this study or the findings specified in this paper.

\section{References}

1. Aarabi B, Hesdorffer DC, Ahn ES, Aresco C, Scalea TM, Eisenberg HM: Outcome following decompressive craniectomy for malignant swelling due to severe head injury. J Neurosurg 104:469-479, 2006

2. Albanese J, Leone M, Alliez JR, Kaya JM, Antonini F, Alliez B, et al: Decompressive craniectomy for severe traumatic brain injury: evaluation of the effects at one year. Crit Care Med 31:2535-2538, 2003

3. Aoki N, Kitahara T, Fukui T, Beck JR, Soma K, Yamamoto W, et al: Management of unruptured intracranial aneurysm in Japan: a Markovian decision analysis with utility measurements based on the Glasgow Outcome Scale. Med Decis Making 18:357-364, 1998

4. Chibbaro S, Tacconi L: Role of decompressive craniectomy in the management of severe head injury with refractory cerebral edema and intractable intracranial pressure. Our experience with 48 cases. Surg Neurol 68:632-638, 2007

5. Coplin WM, Cullen NK, Policherla PN, Vinas FC, Wilseck JM, Zafonte RD, et al: Safety and feasibility of craniectomy with duraplasty as the initial surgical intervention for severe traumatic brain injury. J Trauma 50:1050-1059, 2001

6. Csokay A, Nagy L, Pentelenvi T: "Vascular tunnel" formation to improve the effect of decompressive craniectomy in the treatment of brain swelling caused by trauma and hypoxia. Acta Neurochir (Wien) 143:173-175, 2001

7. De Luca GP, Volpin L, Fornezza U, Cervellini P, Zanusso M, Casentini L, et al: The role of decompressive craniectomy in the treatment of uncontrollable post-traumatic intracranial hypertension. Acta Neurochir Suppl (Wien) 76:401-404, 2000

8. Eisenberg HM, Frankowski RF, Contant CF, Marshall LF, Walker MD: High-dose barbiturate control of elevated intracranial pressure in patients with severe head injury. J Neurosurg 69:15-23, 1988

9. Flint AC, Manley GT, Gean AD, Hemphill JC III, Rosenthal G: Post-operative expansion of hemorrhagic contusions after unilateral decompressive hemicraniectomy in severe traumatic brain injury. J Neurotrauma 25:503-512, 2008
10. Gold M, Siegel J, Russell L, Weinstein M: Cost-Effectiveness in Health and Medicine. New York: Oxford University Press, 1996

11. Guerra WK, Piek J, Gaab MR: Decompressive craniectomy to treat intracranial hypertension in head injury patients. Intensive Care Med 25:1327-1329, 1999

12. Howard JL, Cipolle MD, Anderson M, Sabella V, Shollenberger D, Li PM, et al: Outcome after decompressive craniectomy for the treatment of severe traumatic brain injury. J Trauma 65:380-386, 2008

13. Hutchinson PJ, Corteen E, Czosnyka M, Mendelow AD, Menon DK, Mitchell P, et al: Decompressive craniectomy in traumatic brain injury: the randomized multicenter RESCUEicp study (www.RESCUEicp.com). Acta Neurochir Suppl 96:17-20, 2006

14. Kontopoulos V, Foroglou N, Patsalas J, Magras J, Foroglou G, Yiannakou-Pephtoulidou M, et al: Decompressive craniectomy for the management of patients with refractory hypertension: should it be reconsidered? Acta Neurochir (Wien) 144:791-796, 2002

15. Kunze E, Meixensberger J, Janka M, Sörensen N, Roosen K: Decompressive craniectomy in patients with uncontrollable intracranial hypertension. Acta Neurochir Suppl 71:16-18, 1998

16. Lee MC, Frank JI, Kahana M, Tonsgard JH, Frim DM: Decompressive hemicraniectomy in a 6-year-old male after unilateral hemispheric stroke. Case report and review. Pediatr Neurosurg 38:181-185, 2003

17. Marshall LF, Smith RW, Shapiro HM: The outcome with aggressive treatment in severe head injuries. Part II: acute and chronic barbiturate administration in the management of head injury. J Neurosurg 50:26-30, 1979

18. Meier U,Lemcke J, Reyer T, Gräwe A: Decompressive craniectomy for severe head injury in patients with major extracranial injuries. Acta Neurochir Suppl 96:373-376, 2006

19. Messing-Jünger AM, Marzog J, Wöbker G, Sabel M, Bock WJ: Decompressive craniectomy in severe brain injury. Zentralbl Neurochir 64:171-177, 2003

20. Miller JD, Becker DP, Ward JD, Sullivan HG, Adams WE, Rosner MJ: Significance of intracranial hypertension in severe head injury. J Neurosurg 47:503-516, 1977

21. Morgalla MH, Will BE, Roser F, Tatagiba M: Do long-term results justify decompressive craniectomy after severe traumatic brain injury? J Neurosurg 109:685-690, 2008

22. Münch E, Horn P, Schurer L, Piepgras A, Paul T, Schmiedek P: Management of severe traumatic brain injury by decompressive craniectomy. Neurosurgery 47:315-322, 2000

23. Narayan RK, Kishore PR, Becker DP, Ward JD, Enas GG, Greenberg RP, et al: Intracranial pressure: to monitor or not to monitor? A review of our experience with severe head injury. J Neurosurg 56:650-659, 1982

24. Ogawa M, Minami T, Katsurada K, Sugimoto T: Evaluation of external cranial decompression for traumatic acute brain swelling. Med J Osaka Univ 25:73-78, 1974

25. Olivecrona M, Rodling-Wahlström M, Naredi S, Koskinen LO: Effective ICP reduction by decompressive craniectomy in patients with severe traumatic brain injury treated by an ICP-targeted therapy. J Neurotrauma 24:927-935, 2007

26. Patel HC, Menon DK, Tebbs S, Hawker R, Hutchinson PJ, Kirkpatrick PJ: Specialist neurocritical care and outcome from head injury. Intensive Care Med 28:547-553, 2002

27. Polin RS, Shaffrey ME, Bogaev CA, Tisdale N, Germanson $\mathrm{T}$, Bocchicchio B, et al: Decompressive bifrontal craniectomy in the treatment of severe refractory posttraumatic cerebral edema. Neurosurgery 41:84-92, 1997

28. Pompucci A, De Bonis P, Pettorini B, Petrella G, Di Chirico A, Anile C: Decompressive craniectomy for traumatic brain injury: patient age and outcome. J Neurotrauma 24:11821188,2007 


\section{Quality of life after hemicraniectomy for TBI}

29. Razack N, Singh RV, Petrin D, Villanueva P, Green BA: Bilateral craniotomies for blunt head trauma. J Trauma 43:840843, 1997

30. Sahuquillo J, Arikan F: Decompressive craniectomy for the treatment of refractory high intracranial pressure in traumatic brain injury. Cochrane Database Syst Rev CD003983, 2006

31. Chibbaro S, Marsella M, Romano A, Ippolito S, Benericetti E: Combined internal uncusectomy and decompressive craniectomy for the treatment of severe closed head injury: experience with 80 cases. J Neurosurg 108:74-79, 2008

32. Schneider GH, Bardt T, Lanksch WR, Unterberg A: Decompressive craniectomy following traumatic brain injury: ICP, CPP and neurological outcome. Acta Neurochir Suppl 81:77-79, 2002

33. Skoglund TS, Eriksson-Ritzén C, Jensen C, Rydenhag B: Aspects on decompressive craniectomy in patients with traumatic head injuries. J Neurotrauma 23:1502-1509, 2006

34. Soukiasian HJ, Hui T, Avital I, Eby J, Thompson R, Kleisli $\mathrm{T}$, et al: Decompressive craniectomy in trauma patients with severe brain injury. Am Surg 68:1066-1071, 2002

35. Timofeev I, Kirkpatrick PJ, Corteen E, Hiler M, Czosnyka M, Menon DK, et al: Decompressive craniectomy in traumatic brain injury: outcome following protocol-driven therapy. Acta Neurochir Suppl 96:11-16, 2006

36. Ucar T, Akyuz M, Kazan S, Tuncer R: Role of decompressive surgery in the management of severe head injuries: prognostic factors and patient selection. J Neurotrauma 22:1311-1318, 2005

37. Whitfield PC, Patel H, Hutchinson PJ, Czosnyka M, Parry D, Menon D, et al: Bifrontal decompressive craniectomy in the management of posttraumatic intracranial hypertension. Br J Neurosurg 15:500-507, 2001

38. Xiong G, Wang J, Yang P, Huang W: Application of inferior major bone flap craniotomy decompression in brain injury. Chin J Traumatol 4:126-128, 2001

39. Yang XF, Wen L, Shen F, Li G, Lou R, Liu WG, et al: Surgical complications secondary to decompressive craniectomy in patients with a head injury: a series of 108 consecutive cases. Acta Neurochir (Wien) 150:1241-1248, 2008

40. Yoo DS, Kim DS, Cho KS, Huh PW, Park CK, Kang JK: Ventricular pressure monitoring during bilateral decompression with dural expansion. J Neurosurg 91:953-959, 1999

Manuscript submitted February 3, 2009.

Accepted March 27, 2009.

Address correspondence to: Shabbar F. Danish, M.D., Division of Neurosurgery, UMDNJ-Robert Wood Johnson Medical School, 125 Paterson Street, CAB 2100, New Brunswick, New Jersey 08901. email: danishsh@umdnj.edu. 